\title{
Parasitose Palpebral por Carraça: Caso Clínico e Revisão da Literatura
}

\section{Tick Infestation of the Eyelid: Case Report and Literature Review}

Jorge MOREIRA ${ }^{1}$, Tiago MAIO ${ }^{1}$, Filipa SAMPAIO ${ }^{1}$

Acta Med Port 2018 Feb;31(2):126-128 - https://doi.org/10.20344/amp.9442

\section{RESUMO}

No âmbito da prática clínica oftalmológica, as parasitoses por carraças são incomuns. Os autores descrevem o caso clínico de uma doente de 73 anos observada por edema e eritema da pálpebra superior direita. O exame oftalmológico revelou uma carraça aderente à margem palpebral. A carraça foi removida usando uma pinça fina, e poucos dias após, houve regressão total dos sinais inflamatórios, sem registo de complicações. O parasitismo por carraças representa uma ameaça para a Saúde Pública, pois as carraças são vetores de inúmeros agentes infeciosos responsáveis por patologias potencialmente graves, como a doença de Lyme. As carraças podem também induzir reações cutâneas locais e, mais raramente, paralisia neuromuscular. A morbilidade associada à picada da carraça aumenta com a duração da parasitação, pelo que a carraça deve ser removida o mais rápido possível, e os doentes devem ser alertados para os sinais de possíveis complicações locais e sistémicas.

Palavras-chave: Doenças das Pálpebras; Infecções Oculares Parasitárias; Infestações por Carraça

\section{ABSTRACT}

Tick infestation is rarely seen in ophthalmological practice. We report the case of a 73-year-old woman who presented with edema and erythema of her right upper eyelid. Biomicroscopic examination revealed a tick firmly attached to the eyelid margin. The tick was successfully removed using fine tweezers, and within a few days, the patient had fully recovered without sequelae. Ticks are a threat to public health as they are known vectors of numerous infectious agents responsible for serious pathologies such as Lyme disease. Ticks may also induce cutaneous local reactions, and more rarely, tick paralysis. Since morbidity increases substantially with the duration of the infestation, the tick should be completely removed as soon as possible, and patients should be aware about possible signs of tick related diseases.

Keywords: Eye Infections, Parasitic; Eyelid Diseases; Eyelids; Tick Infestations

\section{INTRODUÇÃO}

As carraças são artrópodes ectoparasitas, hematófagos estritos, que parasitam uma ampla variedade de hospedeiros vertebrados como mamíferos, aves, répteis e anfíbios.

Elas representam um considerável problema para a Saúde Pública, pois são vetores de vários agentes patogénicos responsáveis por doenças infeciosas como riquetsioses, borrelioses, erliquioses, tularémia, babesioses e arboviroses. ${ }^{1}$ Adicionalmente, a presença da carraça na pele pode complicar com formação de granulomas e abcessos. ${ }^{2}$

No âmbito da prática clínica oftalmológica, as parasitoses por carraças são incomuns. ${ }^{2,3}$ Os autores descrevem o caso clínico de uma doente observada por blefarite causada por picada de carraça.

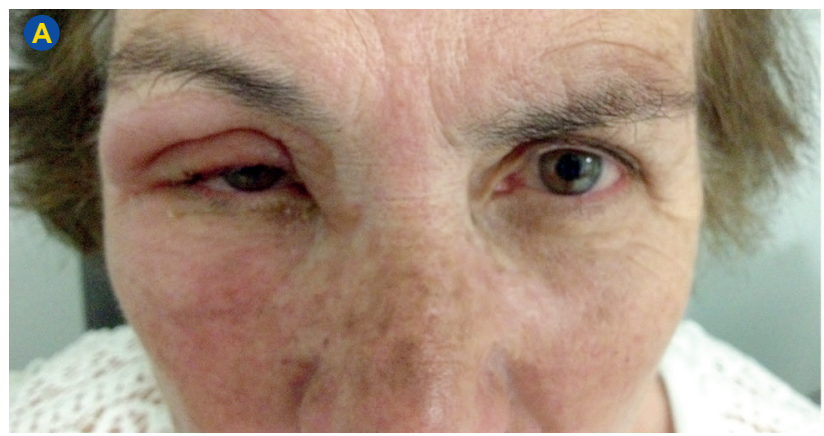

Figura 1 - Edema e eritema da pálpebra superior direita (A, B)

1. Serviço de Oftalmologia. Hospital Pedro Hispano. Matosinhos. Portugal.

$\bowtie$ Autor correspondente: Jorge Moreira. jorgemoreira.fm@gmail.com

Recebido: 15 de julho de 2017 - Aceite: 26 de setembro de 2017| Copyright $\odot$ Ordem dos Médicos 2018 )

\section{CASO CLÍNICO}

Descreve-se o caso de uma doente de 73 anos, que recorreu ao serviço de urgência, por ter acordado com edema e eritema ligeiramente pruriginoso da pálpebra superior direita. Negou dor ou outras queixas oculares. Não tinha sintomas sistémicos e os seus antecedentes pessoais eram irrelevantes. A doente era agricultora e tinha animais domésticos (cães e gatos).

Ao exame oftalmológico apresentava edema e eritema mal definido da pálpebra superior direita (Fig.s 1A e 1B). A observação à biomicroscopia revelou uma carraça firmemente aderente à margem da pálpebra superior (Fig. 2). $\mathrm{O}$ restante exame ocular, incluindo fundoscopia não mostrou alterações.

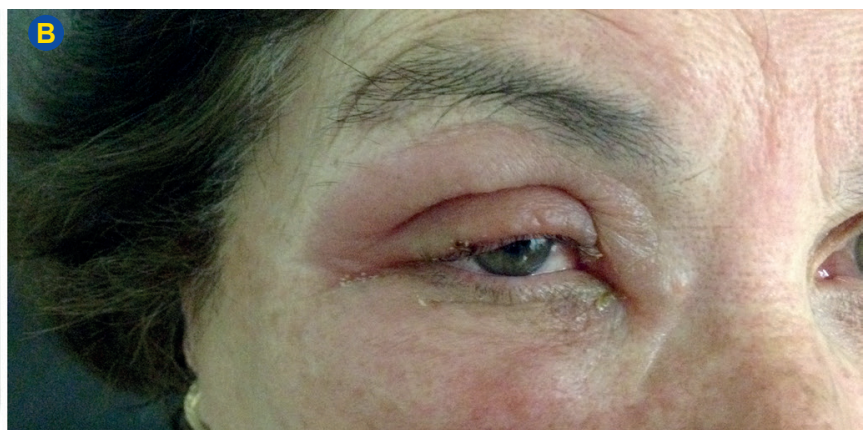


Procedeu-se à remoção da carraça com recurso a uma pinça fina, seguida de desinfeção com iodopovidona, e confirmou-se que a carraça removida estava intacta.

A doente foi medicada com a associação tópica de prednisolona $2,5 \mathrm{mg} / \mathrm{g}$ e cloranfenicol $10 \mathrm{mg} / \mathrm{g}$, aplicada duas vezes/dia. Na reavaliação, quatro dias depois, observou-se regressão total dos sinais inflamatórios.

A doente foi alertada para os sinais e sintomas de possíveis complicações locais ou sistémicas, e foi aconselhada a adotar medidas preventivas, incluindo desparasitação dos animais domésticos. No período de seguimento de dois meses não se registaram intercorrências.

\section{DISCUSSÃO}

O parasitismo dos tecidos oculares por carraças é raro. Quando envolve a região ocular, a pálpebra é a localização mais frequentemente afetada. Contudo, estão também descritos casos de infestação por carraças a nível da conjuntiva. $^{2-9} \mathrm{Na}$ pálpebra, a carraça localiza-se, preferencialmente, na margem palpebral, e o quadro clínico varia desde um prurido ligeiro a uma blefarite grave. ${ }^{6}$ Outras manifestações clínicas oftalmológicas incluem conjuntivite, uveíte e queratite. $^{2}$

Nos orifícios das glândulas de meibomius, as carraças apresentam-se frequentemente como um nódulo palpebral que pode mimetizar lesões cutâneas, incluindo nevo mela- nocítico, quisto epidermóide ou angioma. ${ }^{6,8}$ Adicionalmente, a localização na margem palpebral é facilmente ocultada pelos cílios palpebrais, tornando a sua deteção mais díficil. ${ }^{6}$

O parasitismo por carraças pode causar morbilidade significativa, quer pela possibilidade de transmissão de infeções sistémicas, quer pela ação direta da carraça, incluindo reações de hipersensibilidade, reação de corpo estranho, e complicações neurológicas induzidas por libertação de neurotoxinas. . $^{3,5}$

O risco de transmissão de doenças infeciosas aumenta com a duração da parasitação. Esse aumento é significativo a partir das 24 horas, e é especialmente alto após as 48 horas. ${ }^{3}$ Assim, a remoção deve ser efetuada o mais cedo possível. Estão descritas várias técnicas para remover as carraças, sendo fundamental assegurar que a carraça seja removida intacta. As evidências clínicas sugerem que os métodos químicos, incluindo, aplicação de verniz ungueal, óleos vegetais, vaselina, vinagre, gasolina ou álcool a $70 \%$, usados para facilitar o despreendimento da carraça, são ineficazes, e podem aumentar o risco de transmissão de infeções, ao estimular a secreção salivar da carraça. ${ }^{7,10}$ Adicionalmente, o uso de substâncias oclusivas, com o objetivo de asfixiar o parasita, é ineficaz, pois a frequência respiratória da carraça é extremamente baixa. ${ }^{10}$ Acresce, que no contexto oftalmológico, a maioria desses agentes químicos deverão ser evitados, pelo risco de irritação ocular. ${ }^{7}$

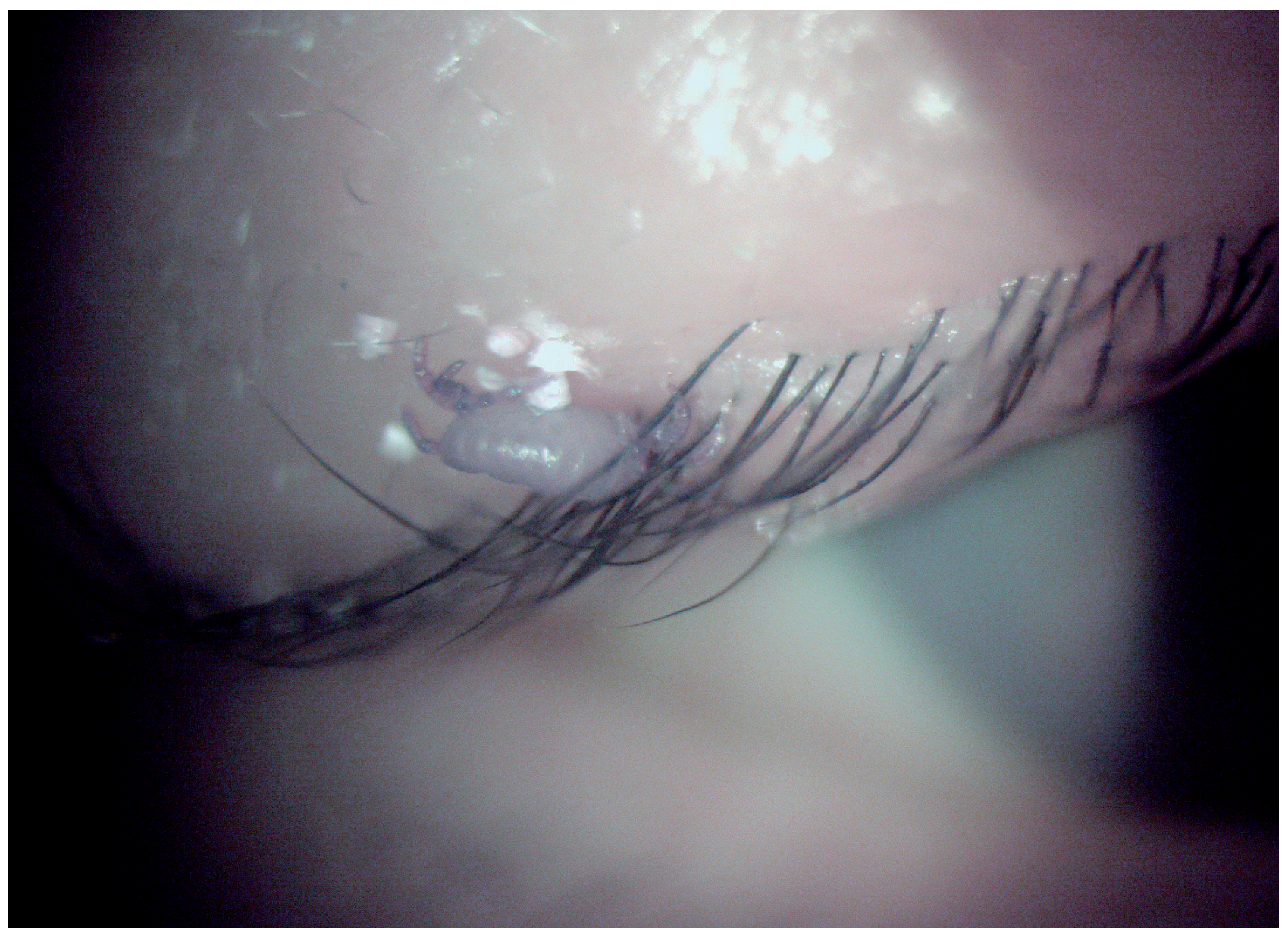

Figura 2 - Carraça aderente à margem palpebral 
A técnica recomendada consiste na extração mecânica da carraça usando uma pinça fina de bordos lisos, introduzida entre a cabeça da carraça e a superfície cutânea, com o cuidado para a remover completamente. . $^{3,10,11}$ Durante o processo de remoção deve evitar-se esmagar a carraça, pois pode aumentar o risco da carraça regurgitar, com subsequente libertação de toxinas e agentes infeciosos. ${ }^{7} \mathrm{~A}$ torção da carraça, também não é aconselhável, devido ao risco de quebrar as peças bucais do parasita. ${ }^{10,11}$

No que concerne à realização de testes serológicos e profilaxia antibiótica, estas medidas não são recomendadas por rotina. ${ }^{10}$

Após a remoção da carraça, as pessoas devem ser alertadas para os sinais e sintomas de possíveis complicações locais ou sistémicas associadas à picada de carraça, incluindo febre e lesões cutâneas no local da picada. ${ }^{10,11}$

Nas últimas décadas tem-se observado uma incidência crescente das doenças relacionadas com as carraças, e existe a preocupação de que num futuro próximo irão representar uma ameaça ainda maior para a Saúde Pública, a nível mundial. ${ }^{12}$ As alterações climáticas inerentes ao aquecimento global, registado nos últimos anos, com consequentes alterações nos ecossistemas têm contribuído para esse aumento. ${ }^{12}$ Portugal não é exceção, no nosso

\section{REFERÊNCIAS}

1. Silva MM, Santos AS, Formosinho P, Bacellar F. Carraças associadas a patologias infecciosas em Portugal. Acta Med Port. 2006;19:39-48.

2. Santos-Bueso E, Calvo-González C, Díaz-Valle D, Benítez-delCastillo JM, García-Sánchez J. Eyelid tick bite. Arch Soc Esp Oftalmol. 2006;81:173-5.

3. Celebi AR, Orkun O. A rare case of tick infestation of the eyelid: case report and literature review. Rev Bras Oftalmol. 2016;75:144-6.

4. Singh M, Gopalakrishnakone P, Yeoh RL. Ixodes tick infestation of the eyelid of a child. Can J Ophthalmol. 2006;41:783-4.

5. McLeod BK. Sheep tick in the eyelid. Br J Ophthalmol. 1986;70:75-6.

6. Rai R, Yoon MK, Stacy RC. Tick infestation of the eyelid with histopathologic characterization. Ophthal Plast Reconstr Surg. 2016;32:e55-8. país existem condições climáticas, ecológicas e ambientais favoráveis ao desenvolvimento e manutenção das carraças, o que reforça a necessidade de implementação contínua de medidas de controlo contra este parasita e das doenças a ele associadas.

\section{PROTECÇÃO DE PESSOAS E ANIMAIS}

Os autores declaram que os procedimentos seguidos estavam de acordo com os regulamentos estabelecidos pelos responsáveis da Comissão de Investigação Clínica e Ética e de acordo com a Declaração de Helsínquia da Associação Médica Mundial.

\section{CONFIDENCIALIDADE DOS DADOS}

Consentimento do doente obtido.

\section{CONFLITOS DE INTERESSE}

Os autores declaram não terem qualquer conflito de interesse relativamente ao presente artigo.

\section{FONTES DE FINANCIAMENTO}

Os autores declaram não ter recebido subsídios ou bolsas para a elaboração do artigo.

7. Price KM, Woodward JA. Management of tick infestation of the eyelid Ophthal Plast Reconstr Surg. 2009;25:328-30.

8. Uzun A, Gok M, Iscanli MD. Tick infestation of eyelid: two case reports. Turk J Ophthalmol. 2016;46:248-50.

9. Celik E, Turkoglu EB, Boz AA, Alagoz G. Conjunctival attachment of a tick: case report. Semin Ophthalmol. 2014;29:186-8.

10. Akin Belli A, Dervis E, Kar S, Ergonul O, Gargili A. Revisiting detachment techniques in human-biting ticks. J Am Acad Dermatol. 2016;75:393-7.

11. Aberer E. What should one do in case of a tick bite? Curr Probl Dermatol. 2009;37:155-66.

12. Estrada-Peña A, de la Fuente J. The ecology of ticks and epidemiology of tick-borne viral diseases. Antiviral Res. 2014;108:104-28. 